\title{
Automatic Washing Machine with Direct Current Power Backup
}

\author{
Adenowo A. A. ${ }^{1}$, Yussuff A.I. ${ }^{1}$, Adetona S.O. ${ }^{2}$, Ogunleye O.M. ${ }^{1}$,

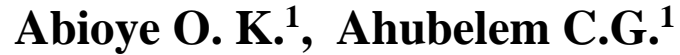 \\ ${ }^{1}$ Electronics and Computer Engineering Department, Lagos State University, Nigeria \\ ${ }^{2}$ Electrical and Electronics Engineering Department, University of Lagos, Lagos, Nigeria
}

Received: $16^{\text {th }}$ April, 2019

*e-mail: abayomi.yussuff@lasu.edu.ng

Accepted: $22^{\text {nd }}$ August, 2019

Published $17^{\text {th }}$ September, 2019

https://doi.org/10.47545/etrj.2019.4.2.051

\begin{abstract}
The design and construction of a simple but efficient automatic washing machine with direct current power backup is presented in this paper. The machine is capable of washing, rinsing and dry-spinning clothes. The intelligence of the machine was based on PIC16f628 microcontroller. This provides the sequence of instructions that controls the machine from start to finish according to the washing mode selected. The machine is robust in design; with local utilization of materials. $3 \mathrm{~kg}$ load of clothes at an average power consumption of 1.91 watt per minute washing cycle was achieved. Furthermore, at power failure, the battery backup was automatically initiated to complete the washing operation.
\end{abstract}

Keywords: Automatic washing machine, Power backup, Local materials, Microcontroller

\section{INTRODUCTION}

A washing machine is a mechanism designed to wash laundry, such as clothing, towels, and sheets. The term is mostly applied only to machines that utilize water as the primary cleaning solution, in contrast to dry cleaning (which uses alternative cleaning fluids, and is performed by specialist businesses) or ultrasonic cleaners [1]. Laundry washing involves immersing, dipping, rubbing, or scrubbing in water, usually accompanied by soap, detergent, or bleach. Cloth washing is an essential part of human life. However, it involves considerable time, effort, and energy, which may be sometimes considered undesirable. Prior to the use of washing machines to wash cloths, clothes are washed by laboriously scrubbing each section of cloth over a cement washboard or flat stone with hands immersed in detergents or soda soap that are harmful to the skin. Women are often left to take up this responsibility. The quest for easier way of doing this household chore culminated in the design of hand operated washing machine. This graduated to the invention of electric-powered washing machine. The development trend continued to the design of mechanically timed switch controlled machine which eventually led to the modern day electronic and micro-processor controlled automatic washing machine [2]. It was reported by [1] that Hamilton Smith patented the rotary washing machine in 1858, while [2] and [3] reported that Alva J. Fisher invented the first ever electric-powered washing machine in 1908.

Various design specifications have been adopted in the design of washing machine. A version of pedal powered washing machine was earlier designed [1]. The main structure was built out of modified bicycle frame. The inner drum was mounted on one side of a pedal shaft. The rotational force due to pedalling turns the drum via a drive gear attached to the pedal shaft. A version of pedal powered washing machine similar to the one reported in [1] was designed by [4]. Again, pedal-powered washing machines were also reported in [5-8]. They were all based on simplicity of design and human power as shown in Figure 1.

Various researchers have come up with a variety of automatic washing machines that are based on different control mechanisms. The automatic control of washing machine proposed in [9] used Application Specific Integrated Circuit (ASIC), using a programmed Hardware Description Language (VHDL). However, the control unit of the machine that was proposed in [10] was based on Programmable Logic Controller (PLC); while the intelligent control unit of the one proposed in [11] utilized PIC18F452 microcontroller. The automatic washing machines proposed in [9-11] employed complex approaches in solving what can easily be achieved with a simple technique. Aside identified gap, all the machines lack power backups. 


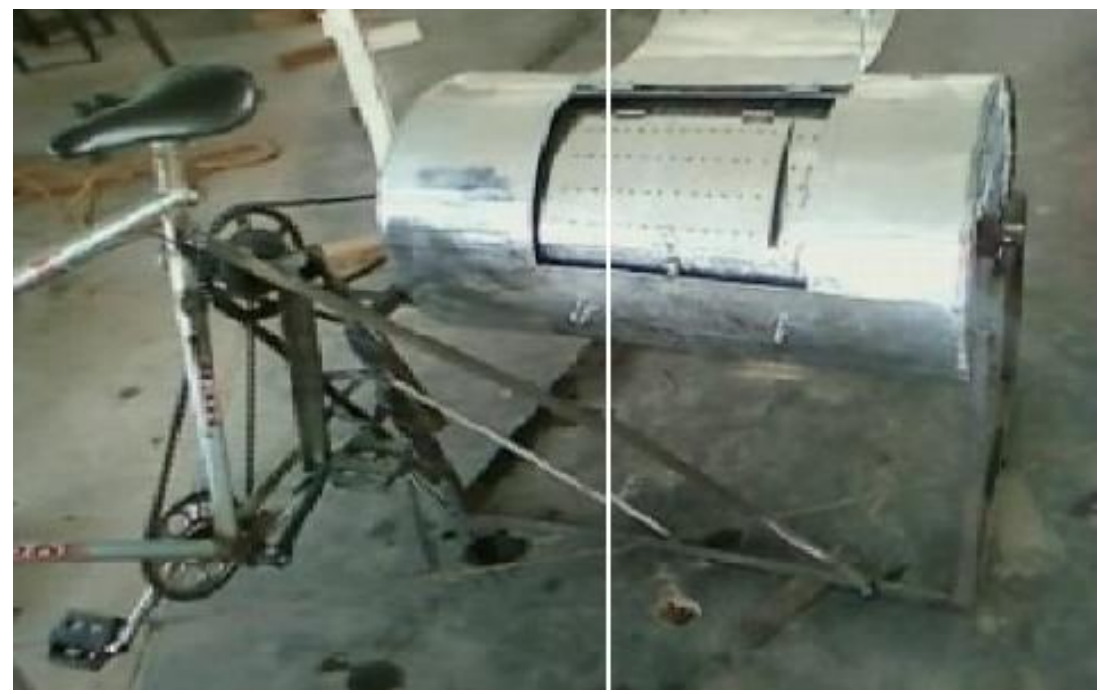

Figure 1. Pedal-powered washing machine [4]

The design and construction of automatic washing machine with battery backed up system is presented. It employs a simple but efficient control mechanism based on PIC16F628 microcontroller with a dc power backup. The battery backup initiates automatically when utility main supply is no longer available.

\section{METHODOLOGY}

Structurally, automatic or semi-automatic washing machines are classified into either top and front loading systems. In top loading washing machines, the lid is located at the top and laundry is loaded from there. It has its washing basket placed vertically. At the centre of it is the agitator which rotates on the vertical axis, turning the clothes. In front loading, the lid is in the front and the laundry is placed in there. There are paddles on the side of the basket which helps move the clothes and stir water while the basket rotates. The paddles help remove dirt from the clothes by creating friction. The basket is placed in the horizontal direction with no use of agitator [12], [13].

The design utilised here combines the technology of top loader and front loader together in a simplified, efficient and affordable manner. The advantages of both technologies are utilized in this design. The salient advantages of this hybrid design include:

a) It is top loader, hence no need of bending down to load in clothes.

b) The washing basket is pivoted horizontally inside a larger tub, hence it uses less water and soap/detergent to wash clothes.

c) Since it is top loader, there is no issue of water leakage through the door or mould built up causing odour as it is found in commercial front loaders.

d) It can be opened in mid cycle to add water or soap if need arises without water spillage through the door opening.

e) It is gentle on clothes as it uses gravity to tumble clothes.

f) The mechanism and control system is not complicated which makes it affordable and serviceable.

g) In case of power failure, there is battery backup power to complete the washing operation. Washing can even be initiated in the absence of mains power supply

\subsection{Design Analysis and Considerations}

The model adopted in this approach involves a combination of perforated inner cylindrical drum, pivoted horizontally, and rotating inside a stationary outer tub that is filled with water at the top to a limited level from bottom. The machine uses electrical power to operate and is fully controlled automatically. Figure 2 shows the block diagram of the proposed machine. 


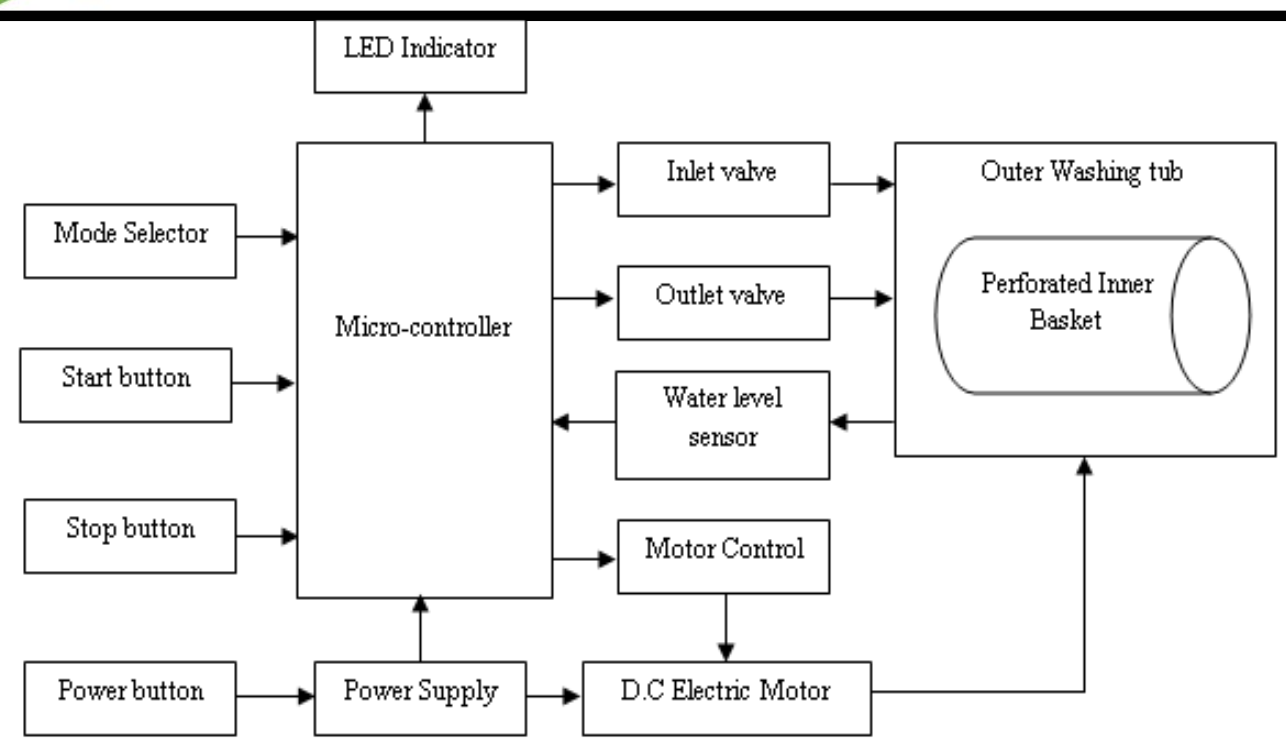

Figure 2. Block diagram of the automatic washing machine

\subsection{Design of Outer Washing Tub (OWT)}

The overall dimension is about $1 \mathrm{~m}^{3}$. It can be operated while standing without bending. To achieve this desired size, the volume of the OWT, $V_{O W T}$, is taken as $0.075 \mathrm{~m}^{3}$; therefore

$V_{\text {OWT }}=$ lenght $_{\text {oWT }} \times$ Width $_{\text {OWT }} \times$ Height $_{\text {OWT }}=0.075 \mathrm{~m}^{3}$

It is assumed that the lenght $t_{O W T}=$ Width $_{O W T}=0.40 \mathrm{~m}$; hence the height of the OWT is obtained as

Height $_{\text {OWT }}=\frac{V_{\text {OWT }}}{\text { lenght }_{\text {OWT }} \times \text { Width }_{\text {OWT }}}=\frac{0.075}{0.40 \times 0.40}=0.47 \mathrm{~m}$

\subsection{Design of Inner Washing Tub (IWT)}

The Inner Washing Drum (IWD) is a cylinder as depicted in Figure 2; hence its volume $V_{I W D}$, is therefore

$V_{I W D}=\pi\left(\text { Radius }_{I W D}\right)^{2} \times$ Height $_{I W D}$

For a specified an average width of $0.05 \mathrm{~m}$, which is maintained round the inner washing tub as it rotates inside the $O W T$, height of the IWD is therefore given as

Height $_{I W D}=$ Width $_{O W T}-(0.05+0.05)=0.40-0.10=0.30 \mathrm{~m} ;$

Again, with a design specification of $V_{I W D}=0.025 \mathrm{~m}^{3}$, the radius of IWD yields

Radius $_{I W D}=\left(\frac{V_{I W D}}{\pi \times \text { Height }_{I W D}}\right)^{\frac{1}{2}}=\left(\frac{0.025}{\pi \times 0.300}\right)^{\frac{1}{2}}=0.150 \mathrm{~m}$

For a design specific water height of $0.13 \mathrm{~m}$ from the base of the $O W T$, the total volume of water $V_{\text {Total }}$ is

$V_{\text {Total }}=0.40 \times 0.40 \times 0.13=0.022 \mathrm{~m}^{3}$

The weight of inner washing drum is $3.5 \mathrm{~kg}$; hence a maximum of $3 \mathrm{~kg}$ of laundry can be loaded.

\subsection{Selection of electric motor}


Information provided in [14] presents a good guide in the choice of the appropriate dc electric motors rating. The experimental result thereof proved that the motor performed without hitches in all tests conducted for loads between $2 \mathrm{~kg}$ and $5 \mathrm{~kg}$. And since the design specification for this washing machine under consideration is for a total load of $3 \mathrm{~kg}$, and from energy consumption pattern in Figure 3, a dc motor of $200 \mathrm{~W}, 24 \mathrm{~V}$, no load current of $0.25 \mathrm{~A}$, maximum load current of 16A, and speed $2800 \mathrm{rpm}$ was selected (for a dc power backup for one hour).

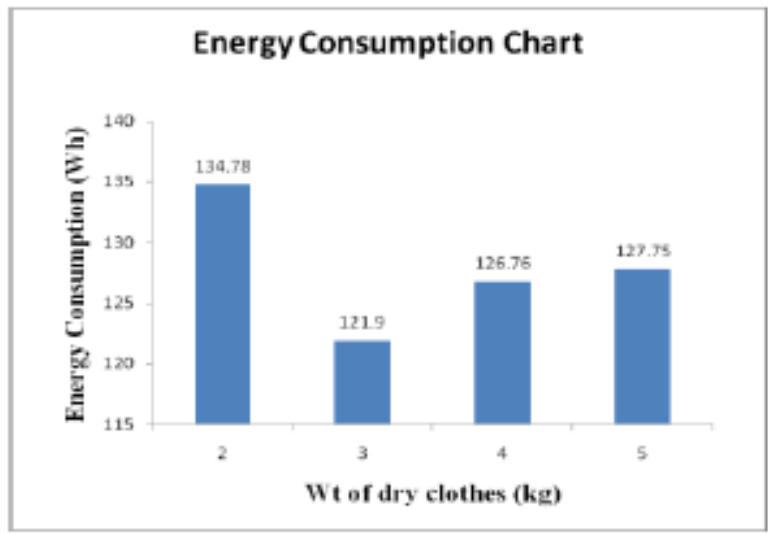

Figure 3. The plot of energy consumption (Wh) versus weight of dry clothes (Kg) [14]

In order to reduce the motor speed by a ratio of 5:1, a pulley of $30.5 \mathrm{~cm}$ diameter was fabricated and installed. The motor speed could also be further varied by varying the applied voltage. Again, high speed spinning was achieved by higher voltage, which is above the normal voltage applied during washing and rinsing.

\subsection{Design of Washing Basket}

The washing basket/drum was fabricated out of a flat stainless steel sheet of $96.5 \mathrm{~cm}$ by $30.5 \mathrm{~cm}$. Stainless steel was chosen among possible alternatives because of the following advantages:

a) It is rust-free. It will be immersed in water always hence, the choice to prevent rust.

b) It is durable. It has a high tensile strength.

c) It can be bent without kinking.

It was perforated before folding to form a cylinder of height $30.5 \mathrm{~cm}$ and a circular face of $30.5 \mathrm{~cm}$ diameter. The circular face was welded to the cylinder to form the washing drum. Three triangular fins (agitator jaws) were also fabricated and fitted inside the drum. This agitates the clothes during wash cycle. The whole washing basket was later banded with aluminium frame for rigid support on its axis of rotation. The inner washing basket design is shown in Figures 4.

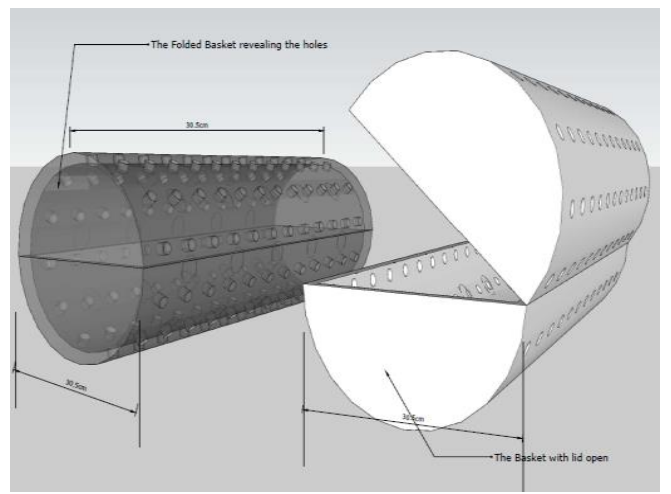

Figure 4. Inner Washing Basket 


\subsection{Fabrication of the Outer Tub}

The outer tub as shown in Figure 5 is made of acrylic material to ensure transparency as required for the machine Other competing material is thick plastic. The acrylic material is $10 \mathrm{~mm}$ thick by the sides that support the bearing whereas, other sides are $5 \mathrm{~mm}$ thick. This material was resized to form a box of dimensions $40 \mathrm{~cm} \times 40 \mathrm{~cm} \times$ $47 \mathrm{~cm}$ which give a volume of $75,000 \mathrm{~cm}^{3}$. The outer tub is shown in Figure 5.

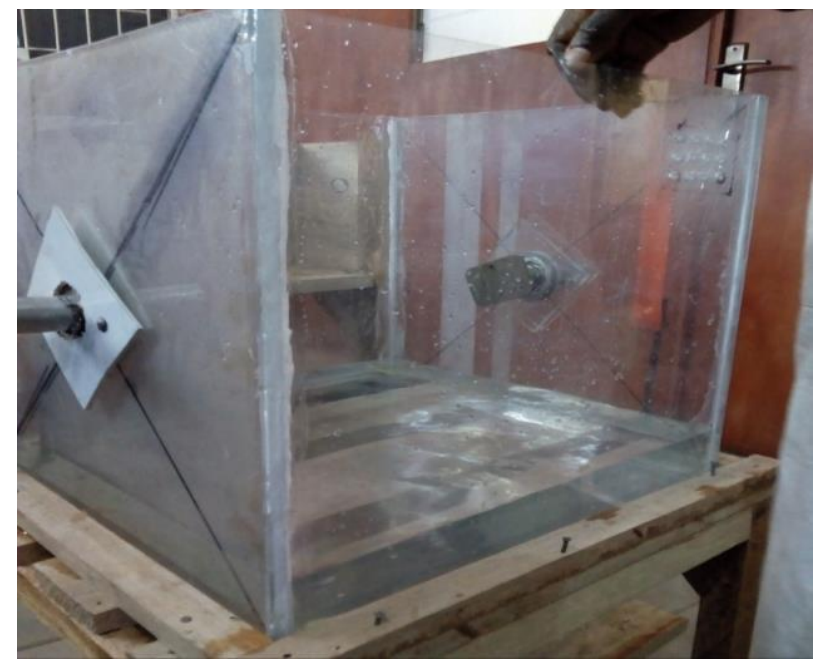

Figure 5. The Outer tub

\subsection{Fabrication of Basic Components of the Washing Machine}

The frame was made of wood, constructed in form of chair with back rest. This is sturdy enough to carry the weight of the whole machine assembly. It provides stability, as well as electrical insulation. The outer metal sheet covering was also screwed to it. Other components of the machine that worth mentioning includes: the bearing support, the pulley, the clamp, the V-belt. The design views of the machine are shown in Figure 6; while finalized view under testing is presented in Figure 7.

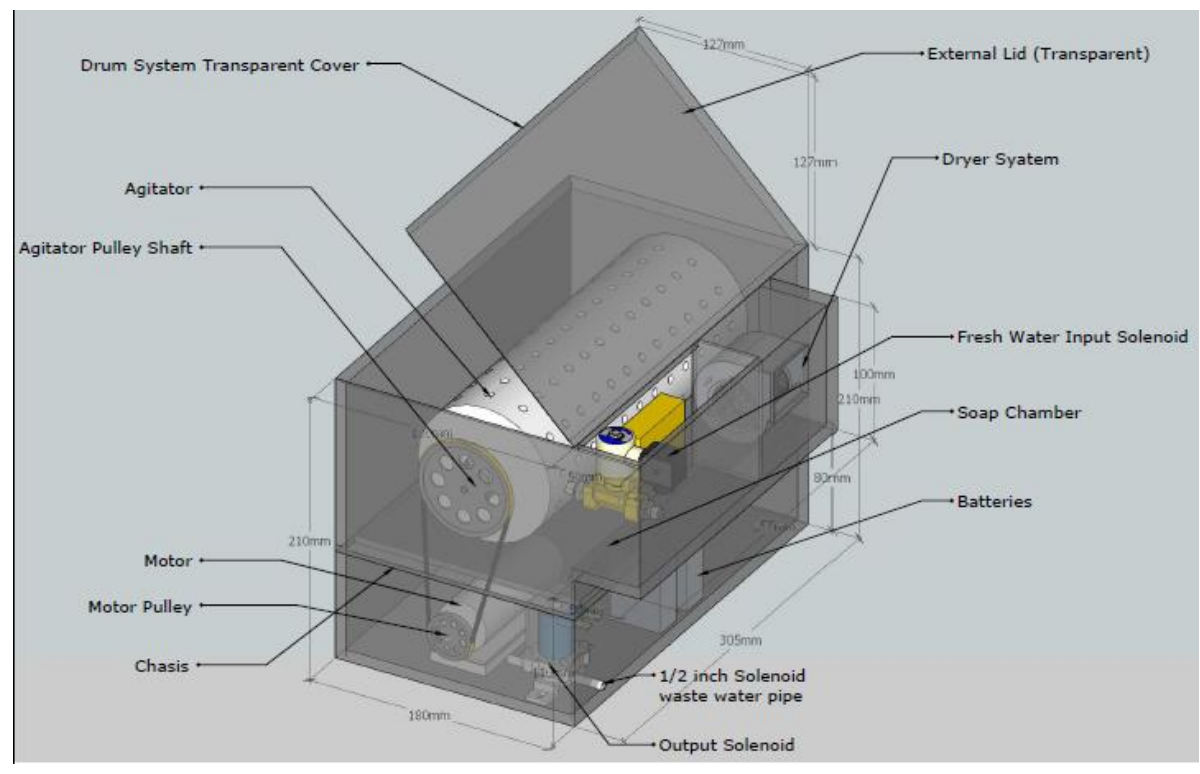

(a) Basic working components of the washing machine 


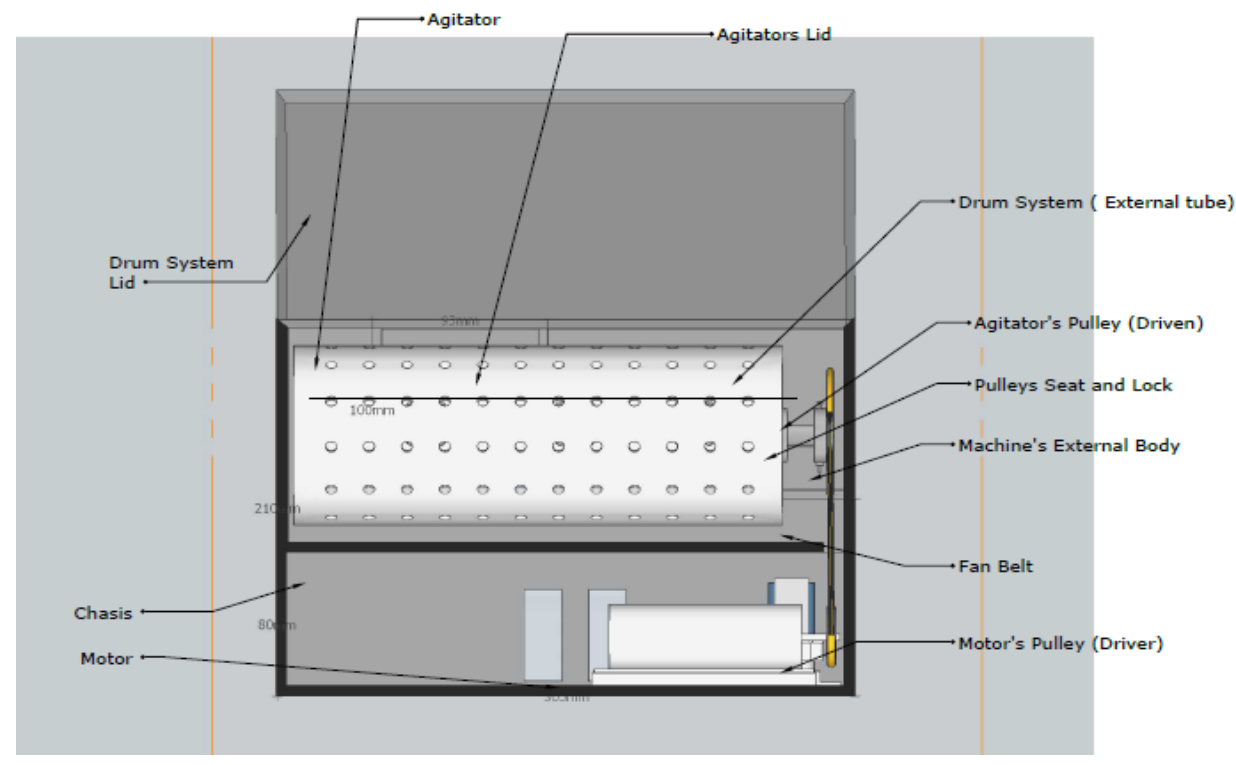

(b) Agitator motor and pulley relationship view

Figure 6. Design views of the machine

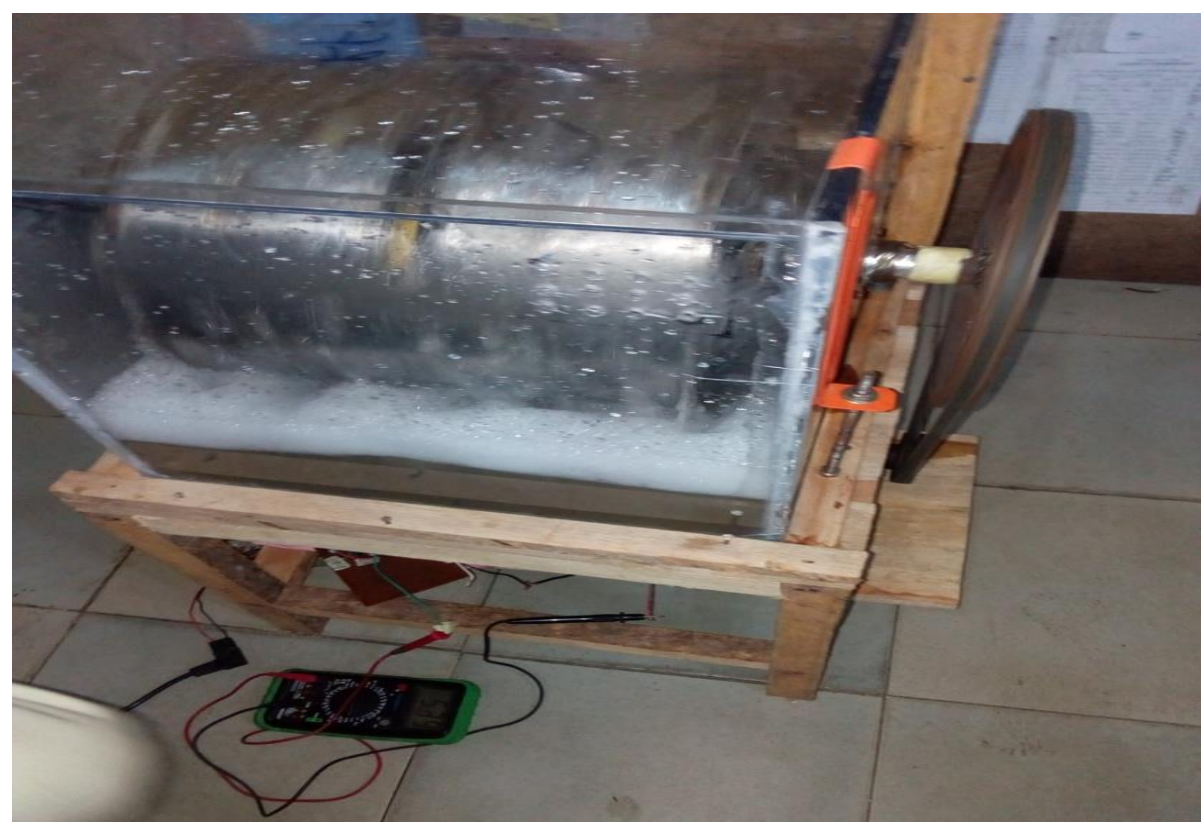

Figure 7. Finalized view of the machine under testing

\subsection{Electrical Power and Control Circuit Design}

The D.C power supply to motor and other units was primarily derived from the mains supply. A centre-tapped 220/24 Volts, 500 VA transformer was used as a step down transformer.

The output was rectified using a 20 A bridge rectifier. This was filtered by capacitors connected across the output of the bridge rectifier in other to remove harmonics and ripples. Several adjustable voltage regulators, LM317 were then configured and trimmed to deliver appropriate voltages to various sections of the circuits. The circuit diagram is shown in Figure 8. 


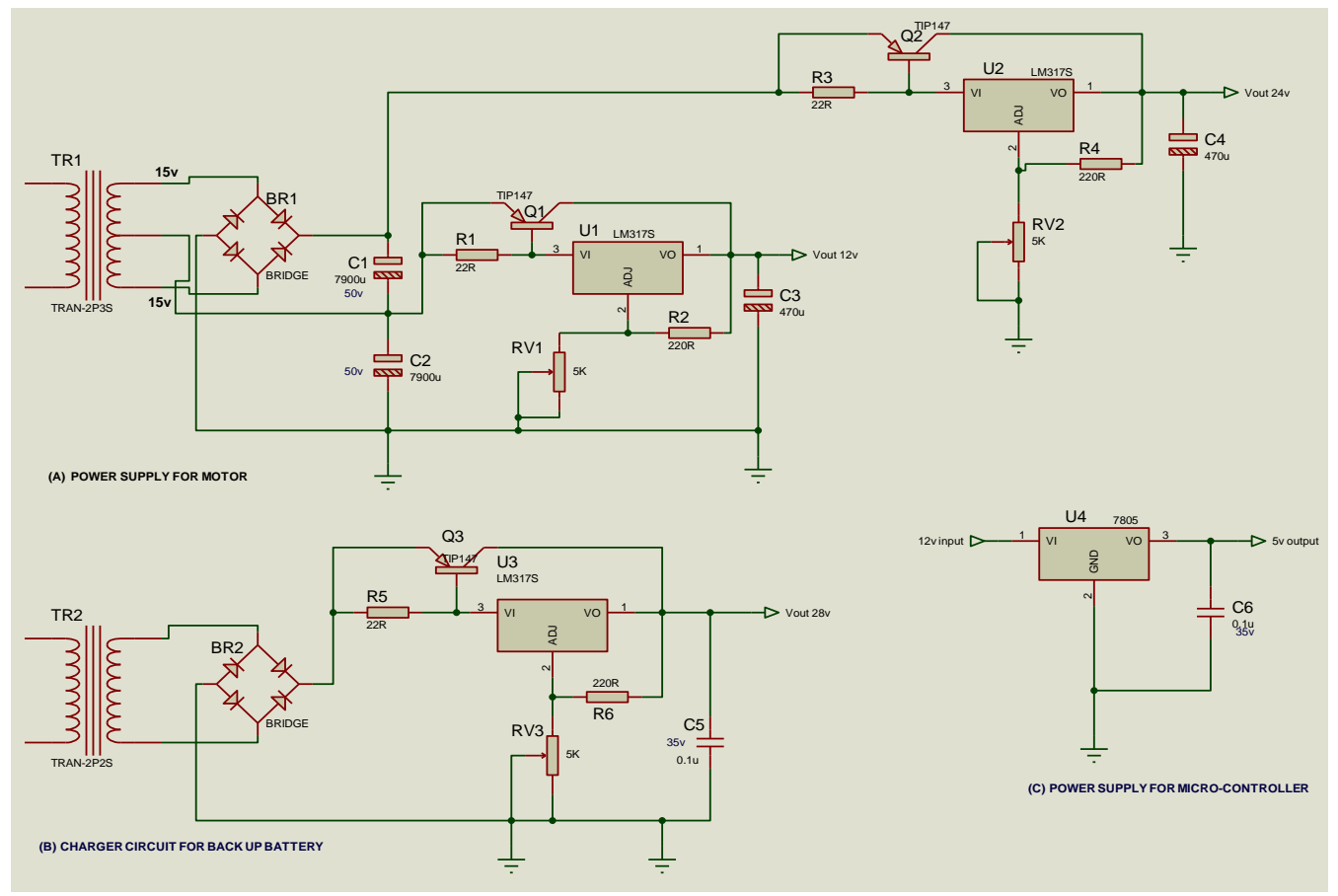

Figure 8. Power Supply circuit to various sections

\subsubsection{Filter Capacitor Selection}

The power supply supplies $16 \mathrm{~A}$, at $24 \mathrm{~V}$ at $50 \mathrm{~Hz}$ frequency at a power factor and ripple factor of 0.8 and 0.25 respectively. The required filter capacitor is

$C=\frac{1}{\left(4 \sqrt{3 f} \lambda R_{L}\right)}$

In equation (3), $R_{L}$ (Load resistance) is $\frac{V_{\text {Load }}}{I_{\text {Load }}}=\frac{24}{16}$ or $1.5 \Omega$; therefore the required $C$ is $7,900 \mu F$.

\subsubsection{Voltage Regulation Selection}

The LM317, an adjustable voltage regulator was used in the design of the regulated output voltages to various sections. The relationship between output voltage and the biasing resistors is

$V_{0}=1.25\left(1+\frac{R_{2}}{R_{1}}\right)$

It has been specified in the data sheet that $R_{1}$ should not be more than $1 \mathrm{k} \Omega$; hence, $R_{1}$ is assumed to be $220 \Omega$. $R_{2}$ is therefore

$R_{2}=R_{1}\left(\frac{V_{0}-1.25}{1.25}\right)=220\left(\frac{24-1.25}{1.25}\right) \cong 4 k \Omega$

In this contribution, a trim potentiometer of $5 \mathrm{k} \Omega$ was then used as $R_{2}$ for the regulator circuit. With duplicates of this circuit, any voltage can then be achieved below or a little above $24 \mathrm{~V}$. The TIP147 serves as a high current pass. It is rated $15 \mathrm{~A}$.

\subsubsection{Intelligent Control Design}


All the control functionalities of the proposed machine were built around 16F628A microcontroller. The controller was designed and programmed to control the supply of water in and out of the washing machine, the timings for washing, rinsing and drying as well as status indication and alarm, all to be performed in sequence automatically. Figure 9 shows the pin assignments of the microcontroller for signals and status indications. The sequence of operations of the machine at different modes is shown with their respective time allocations in Table 1.

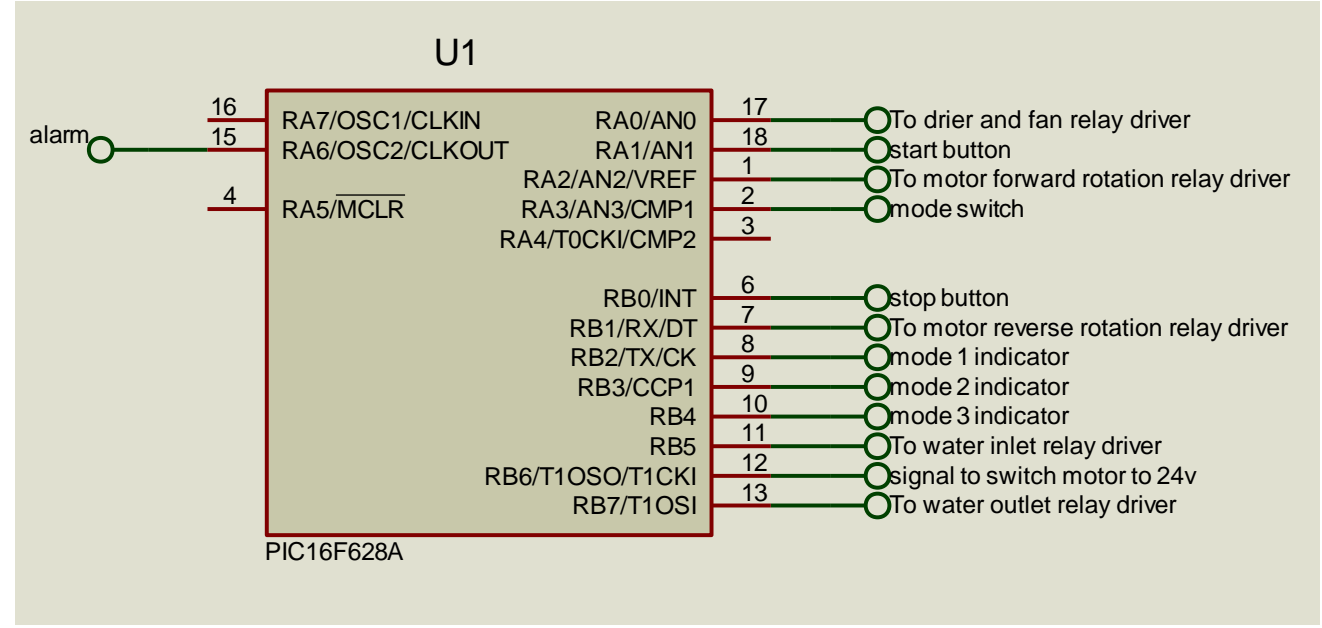

Figure 9. Functions assigned to microcontroller Pins

\section{RESULTS}

The user is required to sort the clothes to be washed according to how dirty they are as well as according to colour. The user loads clothes into the inner tub through the door on top and lock it. Put it in the detergent or liquid soap as desired, and then select the appropriate washing mode out of the three pre-defined mode of washing. Once that is done, the start button is then pressed. The controller will take over from there till finish.

The controller determines the required level of water that is allowed in, controls water exit as well as starting of the motor for washing, rinsing and spinning. It has alarm that alerts the user of the end of the whole washing process. The whole washing process takes about 41 to 56 minutes depending on the mode selected.

\subsection{Backup Power}

This consists of $24 \mathrm{~V}, 17$ AH battery installed with charger to charge the battery. Since the motor is D.C operated, this arrangement readily takes over the supply of power immediately mains supply fails.

Table 1 shows the sequence of timings of various stages of washing operations, depending on the washing mode selected. Mode 1 is to be selected for soft and delicate cloths that require less time to wash. Mode 2 is selected for moderately dirty cloth, while mode 3 is for jeans, towels and very dirty clothes that require much time to wash. It will be observed that the water intake valve opens for $7 / 8$ minutes. This is the time required for the water to reach washing level in the outer washing tub. The flow rate of inlet water and the diameter of the valve accounted for this. The machine performed quietly in all the modes while washing, but during dry-spinning operation, it vibrates.

The testing carried out showed that the motor operates at an average speed of 60 revolutions per minute during washing while the speed increases to 800 revolutions per minute during spinning. The average power consumption was 86 watts when loaded with $3 \mathrm{~kg}$ of dry clothes. It takes an average time of 40 minutes to complete one cycle of washing 
Table 1. Program sequence and timings

\begin{tabular}{|c|l|c|c|c|c|c|c|c|c|c|}
\hline Mode & $\begin{array}{l}\text { Cloth } \\
\text { type }\end{array}$ & $\begin{array}{l}\text { Water } \\
\text { Inlet } \\
\text { valve } \\
\text { Opens } \\
\text { (mins) }\end{array}$ & $\begin{array}{c}\text { Washing } \\
\text { Duration }\end{array}$ & $\begin{array}{c}\text { Water } \\
\text { Outlet } \\
\text { Valve } \\
\text { Opens } \\
\text { (mins) }\end{array}$ & $\begin{array}{c}\text { Water } \\
\text { Inlet and } \\
\text { rinse } \\
\text { operation } \\
\text { (mins) }\end{array}$ & $\begin{array}{c}\text { Water } \\
\text { Outlet } \\
\text { Valve } \\
\text { Opens } \\
\text { (mins) }\end{array}$ & $\begin{array}{l}\text { Water } \\
\text { in and } \\
\text { rinse } \\
\text { (mins) }\end{array}$ & $\begin{array}{l}\text { Water } \\
\text { Outlet } \\
\text { Valve } \\
\text { Opens } \\
\text { (mins) }\end{array}$ & $\begin{array}{l}\text { Spinning } \\
\text { Operation } \\
\text { (mins) }\end{array}$ & Alarm \\
\hline 1 & $\begin{array}{l}\text { Soft } \\
\text { and } \\
\text { delicate }\end{array}$ & 7 & 10 & 2 & 7 & 2 & 7 & 2 & 3 & 1 \\
\hline 2 & $\begin{array}{l}\text { Modera } \\
\text { tely } \\
\text { Dirty } \\
\text { Clothes }\end{array}$ & 7 & 15 & 2 & 7 & 2 & 7 & 2 & 4 & 1 \\
\hline 3 & $\begin{array}{l}\text { Jeans, } \\
\text { Towels } \\
\text { and } \\
\text { very } \\
\text { dirty } \\
\text { clothes }\end{array}$ & 8 & 20 & 2 & 8 & 2 & 8 & 2 & 5 & 1 \\
\hline
\end{tabular}

\section{CONCLUSION}

Design and construction of an automatic washing machine based on D.C power supply and microcontroller controlled is presented in this paper. The design marries the technology of top loader and front loader together in a simplified, efficient and affordable manner. The advantages of both technologies are utilized in the design of the hybrid washing machine such that it saves power, it saves water usage and detergent, it is convenient to operate, it has low maintenance and is affordable. The machine has a D.C power backup to supply power during mains supply failure.

It is recommended that the stability of the machine at high speed of spinning be looked into. This could be done by incorporation of damper. Also, the use of permanent magnet motor can be explored in the design of a low cost, low power automatic washing machine like this.

\section{REFERENCES}

[1] Jadoun R.S.; and Choudhary S.K. (2014). Design and Fabrication of manually driven pedal Powered Washing Machine. Innovative Systems Design and Engineering, 5 (6) 56-68

[2] Akpobi J.A and Okonta J.A. (2007). Design and Construction of a Computer Controlled Clothes Washing Machine. J. Appl. Sci. Environ. Manage. June, 2007, 11 (3) 249 - 251

[3] Mushiri T. and Mugova T.J. (2017). Design and Fabrication of a Pedal Powered Washing Machine, Proceedings of the International Conference on Industrial Engineering and Operations Management Bogota, Colombia, 355-366

[4] Hari Babu, A.V.; Subba R.; Naresh, P., M. V. and Sudhakar R. M. (2016). Performance of a Peddling Washing Machine. International Journal of Current Research, 8 (9) 37865-37870 .

[5] Naresh P.; Jaymin P.; Ashirin B.; and Nirav O. (2013). Peddling Washing Machine. Project Report, Institute of Technology, India

[6] Laundering: A Pedal Powered Washing Machine. Available online at: www.igreenspot.com/launderinga-pedal-powered-washing-machine. Accessed in July, 2018.

[7] Olusegun A.S. (2011). Design and Fabrication of Pedal Powered Laundry Washing Machine. A Final Year Project Report for the Award of B.Eng. in Mechanical Engineering, FUT, Minna, November 2011. 
[8] Ranjan A.; Sharan K.; and Mazumdar S. (2014). Pedal Powered Washing Machine (PPWM). International Journal of Scientific \& Technology Research, 3 (11) 97-103

[9] Gaur N.; and Bansod P.P. (2013). Front End Realization of Automatic Washing Machine. International Journal of Computer Applications, 4th International IT Summit Confluence 2013 - The Next Generation Information Technology Summit, 15-20

[10] Madhuri V. and Yerrathota N. (2016). Automatic Washing Machine Using PLC. International Journal of Latest Trends in Engineering and Technology, 7 (2) 538-543

[11] Embedded System for Automatic Washing Machine Using Microchip PIC18F Series Microcontroller. Available online at: http://asic-soc.blogspot.in/2007/12/embedded-system-for-automatic-washing.html Retrieved July 2018.

[12] Ronca D. (2010). Top 5 benefits of Top-load washers. Available online at: http://home.howstuffworks.com/top-5-benefits-of-top-load-washers.htm. Retrieved $23^{\text {rd }}$ July, 2018.

[13] Clark D. (2014). 6 Major Differences between Front-Loading and Top-Loading Washing Machine. Available online at: www.designlike.com/6-major-differences-between-front-loading-and-top-loadingwashing-machine Retrieved 23rd July 2018.

[14] Beemkumar. N. and Jason A. M. (2015). Energy and Water Consumption Analysis of Washing Process in a Fully Automatic Washing Machine. International Journal of Applied Engineering Research, 10 (11) 10341-10344. 